\title{
Erratum to: Management of embedded metallic stents used in the treatment of grades III and IV subglottic, and upper tracheal stenosis in adults
}

\author{
Khalil Sendi · Talal Al-Khatib • Duha G. Ahmed • \\ Al-Baraa Tonkul
}

Published online: 5 July 2014

(C) Springer-Verlag Berlin Heidelberg 2014

\section{Erratum to: Eur Arch Otorhinolaryngol}

DOI 10.1007/s00405-014-3057-8

The affiliation details of the co-authors were incorrect in the original publication of the article. The correct information is given below.

K. Sendi · A.-B. Tonkul

Otolaryngology Head and Neck Surgery Department, King Abdulaziz University, Jeddah, Saudi Arabia

T. Al-Khatib

Otolaryngology Department, King Abdulaziz University, North of Jeddah Division, Jeddah, Saudi Arabia

The online version of the original article can be found under doi:10.1007/s00405-014-3057-8.

K. Sendi · A.-B. Tonkul

Otolaryngology Head and Neck Surgery Department,

King Abdulaziz University, Jeddah, Saudi Arabia

e-mail: khalilsendi@hotmail.com

A.-B. Tonkul

e-mail: dr.barooo@gmail.com

T. Al-Khatib

Otolaryngology Department, King Abdulaziz University,

North of Jeddah Division, Jeddah, Saudi Arabia

e-mail: talkhatib@kau.edu.sa

D. G. Ahmed $(\bowtie)$

Otolaryngology, Head and Neck Surgery, King Abdulaziz

University, Rabigh Medical College, Jeddah, Saudi Arabia

e-mail: D.gadi4@gmail.com 